University of Wollongong

Research Online

Faculty of Engineering and Information

Faculty of Engineering and Information

Sciences - Papers: Part A

Sciences

$1-1-2016$

Towards organizing smart collaboration and enhancing teamwork performance: a GA-supported system oriented to mobile learning through cloud-based online course

Geng Sun

University of Wollongong, gs147@uowmail.edu.au

Jun Shen

University of Wollongong, jshen@uow.edu.au

Follow this and additional works at: https://ro.uow.edu.au/eispapers

Part of the Engineering Commons, and the Science and Technology Studies Commons

Research Online is the open access institutional repository for the University of Wollongong. For further information contact the UOW Library: research-pubs@uow.edu.au 


\title{
Towards organizing smart collaboration and enhancing teamwork performance: a GA-supported system oriented to mobile learning through cloud-based online course
}

\author{
Abstract \\ At present, people's learning styles become diverse, for which mobile learning is a significant trend that \\ enables distributed learners to achieve collaborative learning and allows them to be engaged in virtual \\ teams to work together. In this research, we develop a system to cope with the problem in current mobile \\ learning circumstance, where learners in virtual teams generally lack proper communications, guidance \\ and assistances between each other. Following the theory of Kolb team learning experience, we use our \\ system, Teamwork as a Service (TaaS), to work in conjunction with cloud-based learning management \\ systems. This system targets at organizing a series of learning activities and then forming a learning flow \\ in order to allow learners to participate into smart collaborations. Executing the five web services of TaaS \\ sequentially, learners can have their collaborative learning arranged in a better environment, where they \\ are able to know about one another, be grouped into cloud-based 'Jigsaw Classroom', plan and publish \\ tasks and supervise other learners mutually. In particular, one primary point of enhancing learners' \\ teamwork performance is to offer them computational choice of task allocation. For this reason, we \\ model the social features related to the collaborative learning activities, and introduce a genetic algorithm \\ (GA) approach to group learners into appropriate teams with two different team formation scenarios. The \\ technical details of the operation principle of GA are illustrated thoroughly. Finally, experimental results \\ are presented to prove our approach is workable to facilitate teamwork with considerations of learner's \\ capabilities and preferences. We also demonstrate our implementation details of the newly designed \\ TaaS over the Amazon cloud and discuss the main improvements for collaborative learning brought by \\ Taas. \\ Disciplines \\ Engineering | Science and Technology Studies

\section{Publication Details} \\ Sun, G. and Shen, J. (2014). Towards organizing smart collaboration and enhancing teamwork \\ performance: a GA-supported system oriented to mobile learning through cloud-based online course. \\ International Journal of Machine Learning and Cybernetics, 7 (3), 391-409.
}

This journal article is available at Research Online: https://ro.uow.edu.au/eispapers/3196 


\title{
Towards Organizing Smart Collaboration and Enhancing Teamwork Performance: A GA-
}

\author{
supported System Oriented to Mobile Learning through Cloud-based Online Course
}

\author{
Geng Sun • Jun Shen
}

\begin{abstract}
At present, people's learning styles become diverse, for which mobile learning is a significant trend that enables distributed learners to achieve collaborative learning and allows them to be engaged in virtual teams to work together. In this research, we develop a system to cope with the problem in current mobile learning circumstance, where learners in virtual teams generally lack proper communications, guidance and assistances between each other. Following the theory of Kolb team learning experience, we use our system, Teamwork as a Service (TaaS), to work in conjunction with cloud-based learning management systems in order to organize a series of learning activities and then form a learning flow. Executing the five web services of TaaS sequentially, learners can have their collaborative learning arranged in a better environment, where they are able to be organized into cloudbased 'Jigsaw Classroom', plan and publish tasks and supervise other learners mutually. In particular, to offer leaners computational choice of task allocation, we model the social features related to the collaborative learning activities, and introduce a genetic algorithm (GA) approach to group learners into appropriate teams with two different team formation scenarios. Finally, experimental results are presented to prove our approach is workable to facilitate teamwork with consideration of learner's capabilities and preferences. We also illustrate our implementation details of the newly designed TaaS over Amazon cloud.
\end{abstract}

Keywords Mobile Cloud, Collaborative Learning, Learning Flow, Genetic Algorithm, Learning Styles, Task Allocation

\section{INTRODUCTION}

The ways of delivering education services are changing very quickly. Learners are no longer limited in the traditional classrooms to acquire those services, as distance education is booming with the assistance of electronic equipment and internetworks. In other words, electronic learning (e-learning) is gaining wider and wider acceptance. A newly emerged form of e-learning is mobile learning (m-learning), which allows learners to participate in learning scenarios utilizing mobile devices regardless of their location [1].

Education providers are interested in delivering services using learning management systems (LMS) to assemble all needed materials, while enabling easy access and user-friendly interfaces [2]. Most LMSs are Web-based and supported by wireless networks. Examples include the well-known Moodle [3], Blackboard [4], Docebo [5], etc. Thus, directly accessing LMSs from mobile devices, either via Web browsers or the latest mobile client programs (i.e. the mobile apps on Android or iOS), is becoming more and more common in learning activities.

M-learning is thriving as it is combined with the new technology of cloud computing. The basis of cloud computing is that computing is arranged in large distributed systems instead of in local computers or remote servers [6]. Benefiting from the combination of mobile and cloud computing, the user is free to access resources and computing capabilities from the cloud on demand through mobile terminals, which could be simply used both as an input and output device [7].

In order to make mobile cloud-based learning feasible, existing LMSs need to be migrated to the cloud or upgraded versions of the original LMSs need to be developed on the cloud platform. Functions supporting collaborative learning are gradually provided in several popular cloud-hosting LMSs [8]. It has been shown that learners find collaborative learning has a

- G. Sun and J. Shen are both with the School of Information Systems and Technology, University of Wollongong, Wollongong, NSW, 2522, Australia E-mail:.gs147@uowmail.edu.au,jshen@uow.edu.au favorable environment to re-occur more and more frequently among learner who have similar learning purpose [9] [10].

To the best of our knowledge, however, there have been comparatively fewer studies aimed at facilitating collaborative learning in the new environment of mobile cloud-based learning and there has been little research aimed at finding ways to enhance learners' teamwork performance in virtual teams. In this paper, we introduce an innovative approach to fill these gaps, using the methodology of social computing to model the features of learning activities and seek the optimal collaborative learning outcomes for learners.

The basic idea of our research is oriented towards, but not limited to, the delivery of university level online courses. The contribution of our research, is a service-oriented system, 'Teamwork as a Service' (TaaS). TaaS is designed to work in conjunction with current cloud-hosting LMSs. It follows the Kolb team learning experience (KTLE), which is an educational approach, to orchestrate a learning flow in order to refine the process of team learning sequentially [11]. During the execution of the learning flow, an environment of social collaboration with more explicit focuses is offered, while a computational optimization process is realized by a genetic algorithm (GA) in order to form appropriate teams and stimulate better teamwork performance.

The rest of the paper is organized as follows: section 2 introduces the identified issues and related work and section 3 describes our methodology, section 4 presents our system framework, section 5 gives the core algorithm used in TaaS, section 6 demonstrates our experiments and section 7 discusses the insights we gained from the system implementation. Finally section 8 concludes the paper and suggests the future work.

\section{CURRENT Issues}

\subsection{Background}

Some researchers have introduced the concept of social computing in order to make collaborative learning easier by organiz- 
ing human behaviors and simplifying human-machine interactions [12]. One of the typical phenomena is the extensive use of Web 2.0 technologies, which bring new ideas for sharing information and offer tools to allow a single task to be controlled by multi-party operations. In [13], LMSs with Web 2.0 functions are also claimed as social software. Hence, the growth of the computer supported collaborative learning (CSCL) becomes pervasive in education and information technology area, and it is clear that the technical support for achieving collaborative learning in mobile cloud-based learning is emerging [14]. Currently, CSCL is used in instructional planning in classrooms, both traditional and online, and from primary school to postgraduate institutions. Like any other instructional activity, it has prescribed practices and strategies, which educators are encouraged to employ in order to use it effectively. Because its use is so widespread, there are innumerable scenarios in the use of CSCL, but there are only several common strategies providing a foundation for group cognition [15]. Learners now have more opportunities to access numerous tools for making collaborative learning activities possible and easier.

While cooperating with the new social computing tools in cloud-hosting LMSs, learners are both the authors of and the audience of the online content relevant to their learning purposes. They now feel free to exchange their ideas, discuss their viewpoints, share their experiences and learn from others' strengths to find and improve their own weaknesses. In this way, the constraints of location, nation are overcome, and the influence scopes of education are expanded [16]. With the explosive distribution of knowledge, learners are naturally drawn into intangible social associations [17]. While learners have different cultural backgrounds, collaboration across multiculture can actually increase positive perception obtained by learners in CSCL environment [18]. Linked by the internet, a social network emerges among learners where learners are clustered in different granularities due to different demands and individual benefits [19]. The two lowest forms of social granularity are the virtual community and the virtual team [13] [20]. Unlike the virtual community, which is more related to learners' interests and with no entry or exit restrictions, the learners who participate in virtual teams are more focused on task-related outcomes and time constraints, often in the form of deadlines [21]. The structure of the virtual team is cohesive as the task requirements and recognitions hold the teams together, and these teams are not disbanded until the tasks are completed. Also, the virtual team has formal lines of authority and roles [13]. After the collaboration, the outcome of a team are usually assessed by specific criteria in order to judge how well the team members have worked together [22].

To make the full use of mobile cloud-based learning, teachers involved in school-based learning have shown great interest in the delivery of online courses which build virtual teams and adopt collaborative learning. Because the virtual team is usually formed in online courses, we concentrate on this learning scenario in particular as our research background.

\subsection{Issues in Collaborative Learning}

Some typical problems, which occur in traditional team-based learning, can also have a negative effect on the virtual team in mobile cloud-based learning:
- $\quad$ Learners belonging to the same team often have different learning styles. Therefore they require diverse learning approaches, tend to learn in different ways and prefer different learning resources [23] [24] [25].

- $\quad$ Each learner's expectations and preferences also influence their motivation to work to the limit of their abilities [23] [26].

- $\quad$ Properly marking each learner based on their individual contributions is still a big challenge, which would take a fairly amount of time and effort to go deeply by teachers. There are few online tools to deal with this problem either.[24] [27]

- The whole team's achievements may be negatively affected by some under-performing learners. [24]

In addition, as the context of mobile cloud-based learning is quite different from traditional learning, learners normally lack the guidance to introduce them into effective direction of the learning path. Thus, once a teamwork assignment is given in an online course, because of geographical separation and in some cases, even time zone differences, learners will face many unpredictable difficulties for which may not be sufficiently prepared.

- Without appropriate face-to-face meetings, communication in mobile cloud-based learning may be insufficient and not as convenient as that in traditional learning. Time zone diversity within a team is not rare [28]. This means that deep discussion is not easy to organize and the delay may cause confusion or misunderstandings to occur. [29].

- $\quad$ Due to team members' diversity and the asynchronicity of online activities, the team leaders are unable to monitor the team members as efficiently as in traditional settings. Also, traditional strategy and direction are sometimes ineffective to run the daily process of the team. Whether a team's task is likely to succeed or fail depends both on its nature and on external factors. In addition, the availability of proper resources and support, as well as information about the difficulty and feasibility of the team's task are often not evaluated suitably in such a context [29].

- It is not easy for the team members to have enough information about each other to a satisfactory extent, Team members may be unfamiliar with one another's strengths and skills [30] and this can also affect the quality of teamwork.

- It is difficult to decide how to get the right set of dedicated and competent team members, which is a major factor in making or breaking the good achievement of a team's tasks. The team members are also uncertain about their common teamwork assignment, including what it is about, how it fits with their roles and expectations, and how it is connected to organizational goals [31].

- $\quad$ There are a number of reasons why the trust among team members can vary. The impossibility of reading facial expression or and body language, participants' feelings of isolation from each other, difficulties in communicating changes in operating procedures, and high stress on individuals because others are depending on them are all factors which influence trust [22]. 
- Currently, for mobile cloud-based learning, there are neither mature methods to assure that the team members' effort and knowledge are totally translated into performance, nor approaches to help learners maintain motivation and attention to their common tasks [32].

- $\quad$ There are also deficiencies in tracking the entire teamwork experience, where problems can be hard to diagnose and solve in a timely manner, while the team learning is actually in progress [32].

\subsection{Related Work}

Some researchers have applied identifying learners' KLS to improving teaching outcomes by recognizing the importance in considering each individual student's needs [33] [34]. Some other researchers also noted that the concept of KLS could also be utilized to assist in structuring virtual learning environments, through adapting the design of online distance courses to accommodate learners' styles [35] [36].

In [37], the authors suggested a way to deal with the online team formation with the assumption that people possess different skills and that each task requires a specific set of skills. They employed a social network to model the capability of potential team members. They created a series of effective algorithms which are able to form teams with a fair allocation of workload, while satisfying the required skills, balancing the conflicting requirements and keeping coordination costs within limits.

The problem of task allocation has been studied by many researchers and GAs have been widely applied, especially when there are problems with large scale and complex structure. For example, [38] presented a GA-based study of two task allocation models in distributed computing systems. A type of GA has also been capable to map tasks dynamically to processors in a heterogeneous distributed system [39].

In [40], the authors presented a framework by which the candidates' knowledge is analyzed. Based on their knowledge and collaboration, a GA was utilized in that framework to select proper personnel and appoint the appropriate team managers and team members. With the wider adoption of social computing, a GA was also employed in some research to organize and manage social knowledge. In [41], the authors introduced a GA-based method to discover the optimal learning path from among numerous candidate courses for undergraduate students.

Researchers have paid attention on how to develop teams in CSCL by presenting a framework with key variables mediating learning-team effectiveness in either face-to-face or online settings, within the perspective of learning-team development [42]. To encourage and help learners to easily participate in collaborative learning, some researchers have also exploited cloud computing to construct the collaborative learning platform in the e-learning environment [43]. Another study combined the cloud with the mobile environment, by providing an application based on the Android OS [44], and it suggested that a mobile collaborative learning cycle was appropriate for both the ubiquitous learning environment and online classes.

Some efforts are made on offering learners collaborative learning tools through introducing the web service technology [45]. Nevertheless, the organization of virtual teams in traditional mobile cloud-based learning lacks mechanisms to control and normalize the whole process, meanwhile, teachers are guiding with more macro-direction than particular instructions. For this reason, it is significant to explore how to provide learners one-stop well-structured collaborative learning experience in mobile cloud-based environment, to help them be more focused on teamwork and offer them computational choices to get into smart collaborative learning scenarios.

\section{Methodology}

\subsection{Teamwork-Enhanced Learning Flow}

As mentioned above, there are quite a few problems involved in building virtual teams and leading them to succeed. In a study of problem-solving teams, social interaction is seen as the key variable [46]. It is essential to provide a shared social context for learners to socialize, learn and construct knowledge [47]. To achieve coordinated collaboration, learners should be aware of three kinds of awareness: social awareness (who is around?), action awareness (what's going on?), and activity awareness (how are things going?).

Mobile learning, especially mobile team learning, is not only the process of knowledge being passed on, but also the process of creating knowledge as a result of interactions between social knowledge and personal knowledge [48]. Mobile learning activities normally consist of two sections: online learning and offline learning [49]. In other words, learners participating in mlearning are able to gain learning opportunities and access educational materials regardless of the internet connection. Because mobile learners are free to download materials into their mobile devices for viewing offline and being introduced and guided in their practices, they do not always stay online to access LMSs and attend tutorials [50]. For mobile collaborative learning, when some work needs equipment and materials other than mobile devices, even more procedures must be completed offline. A new concept, 'online to offline' (O2O), can help organize mobile cloud-based learning [51]. Using this concept, the process logic of mobile team learning can be clearly defined by online systems, including the transaction details and deliverable resources. Hence, while learners are able to accomplish many of their teamwork tasks offline, for some necessary procedures, such as data entry and work submission, they need to go back online to finish. Using online systems to command and restrain offline behaviors also helps to avoid confusion and misunderstanding, while still offering more offline opportunities.

Combining the features of the mobile cloud environment, where applications are normally service-oriented, practitioners and developers are free to choose useful services on demand and compose them together to establish a virtual environment which provides more comprehensive functions than just one application [52]. In such a new environment, a feasible way to realize the whole teamwork-enhanced learning process is to orchestrate a learning flow. Learning flow, a specification of workflow, refers to the formal description of a set of rules and the process during which the learning activities happen and change [53].

Generally, the traditional collaborative learning flow in an online course of mobile cloud-based learning can be abstracted as 'receiving team assignments', 'accessing team learning resources', 'proceeding team learning', 'submitting team outcomes' and 'getting evaluations'. 
By using KTLE as the main concept [11], we implemented a teamwork-enhanced learning flow by automatically interoperating cloud-hosting LMSs and our newly designed system, TaaS.

\subsection{Design of TaaS}

The basic principle of this innovative learning flow execution is that learners and teachers are still using cloud-hosting LMSs to process their daily learning activity. Teachers can assign the team learning assignment with the undergoing online course through cloud-hosting LMSs. If there is a team learning activity (for example, team based assignment) happening, both learners and teachers are free to switch to TaaS, to access functions to facilitate their teamwork or to supervise the whole progress of the learners.

As the cloud-hosting LMS's partner, TaaS is serviceoriented to guarantee flexible interaction with all involved systems, and better to be hosted over cloud to borrow the massive computing power of the cloud. Specifically, utilizing the cloud can enables different levels of access by different education providers with only once large-scale deployment, and preserve TaaS by load balancers in the cloud to ensure robustness, even when there are sudden increases in network traffic. The need for data and computation during the team learning process can be controlled by the cloud, thus the complexity of the system will not be increased by the limitations of the mobile devices. For ease of use and seamless switching between the two systems, once the topics of team learning assignments are released, the first synchronization between TaaS and cloud-hosting LMSs is triggered. Both of them will share the same user information over the whole team learning process.

TaaS aims to build a better social context for collaborative learning. In the learning flow, which is shown as Fig. 1, the 'proceeding learning content activities' is subdivided into the seven modules of KTLE, one or more of which is taken by each of the five web services of TaaS to organize a certain type of learning activity. These services work sequentially as a whole in parallel with the activity of 'accessing learning resource'.

Here, we briefly introduce the idea of how to import social computing into TaaS. There are five web services in TaaS.

- The Survey Service works for the 'introduction to teams' module. It supports a platform for learners to know one another at the beginning of the collaborative learning, usually concurring with the release of the team assignment. Data about each learner's social features are collected, in terms of their learning styles and comprehensive skills.

- The Jigsaw method introduced in [54] is commonly used for deepening learners' understanding of 'team purpose', the three stages of which can be imitated by the Jigsaw Service. It organizes a cloud Jigsaw Classroom containing different forms of meaningful personnel structures for learners to get into efficient discussion about their team assignments.

- $\quad$ The Bulletin Service allows learners to collaboratively define their 'team context' and 'team purpose', by writing down their thoughts about how to accomplish the team assignment. It is also utilized to evaluate each pre-planned task's difficulty and learners' preference regarding it.

- $\quad$ The Inference Service concentrates on assigning the suited 'team membership' for each capable team and allocating the clear-cut 'team role' for each team member. The idea is inspired from [28], which suggests that a solution to facilitate collaboration and reduce conflict is that the leadership of mobile virtual teams can be shared. We purposefully amend it by abolishing the concentrated leadership and share leadership over the both sides of the O2O. Because effective grouping is important for each team of learners to perform better [23] [55] [56], this service takes the responsibility of 'computation', in the narrow sense of social computing, to find out how to group learners into competitive teams. The reasoning process of team formation is supported using a GA method.

- $\quad$ The other duty of the concentrated leadership that monitors team members' work is replaced by mutual supervision among learners, which is conducted by the Monitor Service. It works to regularize learners' behaviors during the 'team action' and 'team process'. Borrowing the idea of 'within team Jigsaw' [57], in each team, each learner is assigned as the coordinator for another.

To model the pedagogical variables, we need to set up parameters relevant to real learning experiences. Notably, Kolb has demonstrated four learning styles, namely accommodating, assimilating, converging and diverging [58] [59]. Basically, the "accommodating" is learning from hands-on practice and intuition rather than logic analysis; the "assimilating” refers

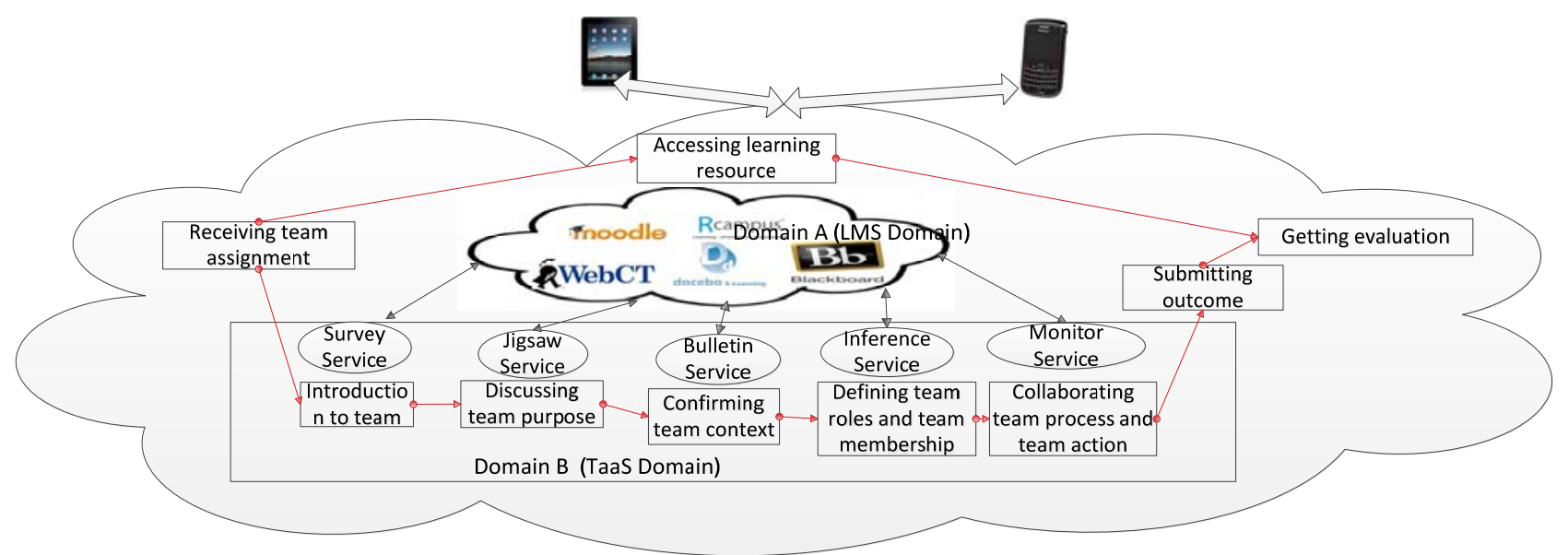

Fig. 1 Teamwork-Enhanced Learning Flow for Mobile Cloud-based Learning 
to discovering and understanding a wide range of information and then categorizing and conforming them into concise and logical forms; the "converging" is to solve problems into practical uses and find solution using learning experiences; and the "diverging" is more relevant to observation at concrete situations from many different viewpoints. Belbin and Loo mapped these four learning styles to four roles (accommodator, assimilator, converger, and diverger) which are equally important and generally existing in an experienced team [60] [61].

In [62], comprehensive teamwork skills are identified as the factors central to whether the learner can play a valuable role in a team and achieve sufficient collaborative learning outcomes. This set of skills is normally reflected by learners' actions and behaviors while they are engaging with other learners sharing the same learning targets. Typical comprehensive teamwork skills include, how attentive they listen to views and opinions of others, to what extent they provide help to others and introduce new ideas, and whether they accomplish a fair share of the teamwork, etc. [62].

\section{SYSTEM FRAMEWORK}

\subsection{The Survey Service}

The Survey Service offers interfaces to learners for answering questionnaires to investigate their capabilities. Considering the limitations of screen size and input method of mobile devices, the surveys are single-choice based. It can be operated as selfassessment or peer-assessment, which means the respondents of the surveys can evaluate themselves or the other teammates working with them. By observing themselves and others behaviors and evaluating the evidence of the individual team members' contributions, learners can give appropriate grades to each question accordingly.

There are five sets of questionnaires pre-installed in the Survey Service, four of which are for the four KLS [58] [59] categories (accommodating, assimilating, converging, diverging), and the last is for comprehensive teamwork skills. In these questionnaires, questions for evaluating learners' KLS were derived from [59], while questions for assessing learners' comprehensive teamwork skills were derived from [63]. These questionnaires can be extended or reduced by teachers manually. Learners can choose one of the ten options to answer each question, which is an integer between 1 and 10, the higher the better.

Let $L^{k}$ denote the $k^{\text {th }}$ learner. In the Survey Service, $L^{k \text {, }}$ capability will be compiled from questionnaires, from both selfassessment and peer-assessment. The results of each question for evaluating $L^{k}$ will be recorded in a matrix in which each column stands for a question, while each row corresponds to a learner who gives the marks. So five matrices are obtained, they are $\left\{A C^{k}\right\},\left\{A S^{k}\right\},\left\{C^{k}\right\},\left\{D^{k}\right\}$ and $\left\{C T^{k}\right\}$. These five abbreviations stand for accommodating, assimilating, converging, diverging and comprehensive teamwork, respectively. For example, the capability of accommodating (AC) of $L^{k}$ can be stated as:

$$
\left\{A C^{k}\right\}=\left(\begin{array}{cccc}
M_{1}^{1} & M_{1}^{2} & \ldots & M_{1}^{n} \\
M_{2}^{1} & M_{2}^{2} & \ldots & M_{2}^{n} \\
\ldots & \ldots & \ldots & \ldots \\
M_{m}^{1} & M_{m}^{2} & \ldots & M_{m}^{n}
\end{array}\right)
$$

where: $M_{m}^{n}$ means the mark for the $n^{\text {th }}$ question of the accommodating aspect, which is given in the $m^{\text {th }}$ assessment, and $M_{m}^{n}$ is an integer between 1 and 10. $n$ depends on the question title's order and $m$ is in accordance with the sequence of questionnaire submission times.

In matrix $\left\{A C^{k}\right\}$, the mean of each column describes the strengths of different types of accommodating, and we use the next equation to calculate the value of accommodating capability of $L^{k}$ :

$$
A C^{k}=\frac{\sum_{j=1}^{m} \sum_{i=1}^{n} M_{j}^{i}}{n m}
$$

In the same way, the Survey Service calculates the values for the other four matrices. Hence, we get these values: $A S^{k}, C^{k}$, $D^{k}$ and $C T^{k}$. As we introduced before, they represent the capability values of assimilating, converging, diverging and comprehensive teamwork skills, respectively. We let a 4-tuple $K L S^{k}$ $=\left\{A C^{k}, A S^{k}, C^{k}, D^{k}\right\}$ denote the KLS capability values of $L^{k}$ as they are closely related.

For self-assessment in a course, which must usually be completed first, learners are not allowed to repeat it. In other words, during the period of one course, if a learner has already answered the questionnaires for evaluating himself/herself, the Survey Service will switch off the entry of self-assessment for him/her. The historical data of his/her survey results collected from other courses are used continually in this course. That is to say, if a learner is a newly registered user of TaaS, the Survey Service will create five new capability matrixes for him/her to record survey results, and these matrixes will be yielded and updated during his/her whole period of learning in different courses using TaaS. If a learner is not a newly registered user of TaaS, the Survey Service has recorded his/her non-null capability values already. The newly collected survey results will be added into his/her capability matrixes rather than replace the historical results.

For peer-assessment in one course, if learners have, at one time, been teammates at any stage of Jigsaw Classroom (section 4.2) or in the ultimate team working towards accomplishing an assignment, they are able to evaluate each other only once. After any change of team structure, the Survey Service releases the surveys to learners for evaluating former teammates mutually. In this way, one learner may evaluate another more than once during the whole process of an online course. Subsequent survey results will not replace those ones given previously, but will appear as new rows at the bottom of their capability matrixes.

The structure of surveys can be manually changed by teachers, by adding or reducing questions, resulting in the number of columns in the corresponding matrix changing. Accordingly, the types of matrix vary with the change of survey structure. 


\subsection{The Jigsaw Service}

As the Jigsaw Classroom [36] has three stages the personnel structure of the first one and the third one is the same. Two key points must be considered: the formation of original teams and expert teams.

For 'initial discussion in original team', the Jigsaw Service groups learners into original four-person teams. First, it extracts all learner information from the Survey Service and triggers a computing process about grouping learners into four-personsized original teams with nearly equal comprehensive teamwork skills $(C T)$ in each group. Second, each learner in one original group is assigned one of the four KLS roles as described in [41] [42]. The method of role assignment is to choose the best player according to each aspect, and if there is anyone leading two aspects in the team, choosing his/her best quality. For example, in an original team, learner A has the highest value of accommodating $(A C)$, s/he is assigned as the 'accommodator' while another learner, B, leads converging $(C)$ and diverging $(D)$ in the team with the addition that $\mathrm{s} / \mathrm{he}$ is better at converging, the Jigsaw Service assigns the 'converger' role to him/her.

For 'joining expert team to refine cognition', the Jigsaw Service arranges learners who played the same role in the original team to join as an expert team. Consequently, there are four expert teams: accommodators, assimilators, convergers and divergers. For 'backing to original group to teach others what was gained in expert group', the Jigsaw Service redirects learners into the original teams from which they have come.

In the cloud Jigsaw Classroom, whenever during the original team learning period or during the expert team learning period, the Jigsaw Service provides a common interface for the whole team where they can interact with each other, it shields the information of other groups. Each modification of team structure in TaaS will be updated to cloud-hosting LMSs. Therefore, learners are also organized into groups in those systems as the same formations in TaaS. Given that most cloudhosting LMSs provide the 'Group' functions as well as abundant tools for supporting collaborative learning, learners benefit from utilizing such conveniences for assisting their discussions in the three stages of the Jigsaw Classroom (see Fig. 2).
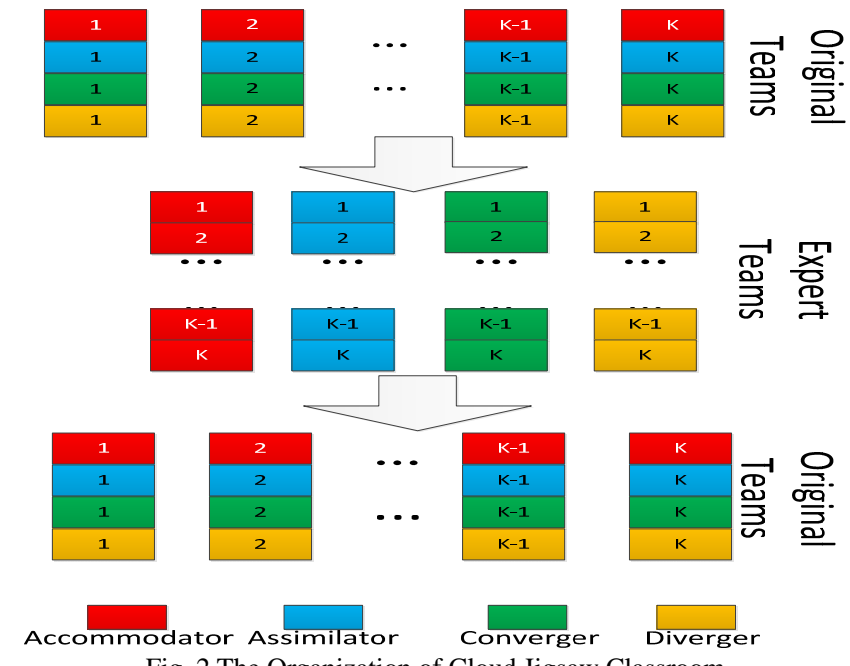

Fig. 2 The Organization of Cloud Jigsaw Classroom

\subsection{The Bulletin Service}

The Bulletin Service borrows the idea from the famous Wiki system [64] to establish a collaborative editing environment for learners to plan the detailed task schedule for completing the team assignment. In the traditional Wiki systems, however, users are required to know some kinds of specific mark-up language in order to publish contents, whereas some typical Wiki systems, such as the most famous Wikipedia, have their particular editing language [65]. As being applied in text management, the Bulletin Service improves the inconvenience by offering the WYSIWYG mode. Hence, learners can type their text content directly to access and edit published task schedules through the user interfaces on mobile devices.

A published task schedule is prepared for the workload of an imaginary team. This consists of: the task topic, the task introduction, several subtasks, stages of each subtask, detailed content and period of each stage, and sequential relationship between subtasks (if a subtask is the premise for another). The content is in text form and the period is counted in days.

The number of subtasks of each task can be pre-set by teachers. Taking an example from real team learning scenarios, we suppose the number is between 3 and 6 and learners are required to consider this task size while they are pre-planning [23]. Before inserting the content of a task, the learner can adjust its structure by adding/reducing the number of subtasks to not more than 6 and not less than 3. S/he can also adjust the structure of each of these by adding/reducing the number of stages.

The subtask's difficulty is marked by expected-achievable values, depending on the publisher and his/her teammates from the same original team of the Jigsaw Classroom. Let a published $S^{i, j}$ represent the $j^{\text {th }}$ subtask of the $i^{\text {th }}$ task. For $S^{i, j}$, the Bulletin Service allows authorized learners to type in a real number between 1 and 10 for each aspect of the KLS, in order to indicate that is to be better completed by a learner who has similar capabilities. The results are recorded in a matrix $\left\{S^{i, j}\right\}$ :

$$
\left\{S^{i, j}\right\}=\left(\begin{array}{cccc}
V_{1}^{1} & V_{1}^{2} & V_{1}^{3} & V_{1}^{4} \\
V_{2}^{1} & V_{2}^{2} & \cdots & V_{2}^{4} \\
\cdots & \cdots & \cdots & \cdots \\
V_{m}^{1} & V_{m}^{2} & V_{m}^{3} & V_{m}^{4}
\end{array}\right)
$$

where $V$ is the value for one aspect of KLS given by one learner, the four columns denote the aspect of accommodating, assimilating, converging and diverging, sequentially, and each row represents the results given by one learner in accordance with time sequence. We use the next equation to calculate the final expected-achievable value, namely $S T^{i j}$, of $S^{i, j}$ :

$$
S T^{i j}=\left\{A C^{i j}, A S^{i j}, C^{i j}, D^{i j}\right\}=\left\{\frac{\sum_{i=1}^{m} V_{i}^{1}}{m}, \frac{\sum_{i=1}^{m} V_{i}^{2}}{m}, \frac{\sum_{i=1}^{m} V_{i}^{3}}{m}, \frac{\sum_{i=1}^{m} V_{i}^{4}}{m}\right\}
$$

Hence a 4-tuple $S T^{i j}=\left\{A C^{i j}, A S^{i j}, C^{i j}, D^{i j}\right\}$ is obtained, where each element is a real number between 1 and 10 .

When examining a task, learners are free to show their preferences for each subtask by choosing one of the five grades. The variable $P_{k}^{i j}$ denotes the preference grade of the $S^{i, j}$, given by the $k^{\text {th }}$ learner. The $P_{k}^{i j}$ is an integer between 1 and 5 , the higher the grade, the higher the learner's preference for doing 


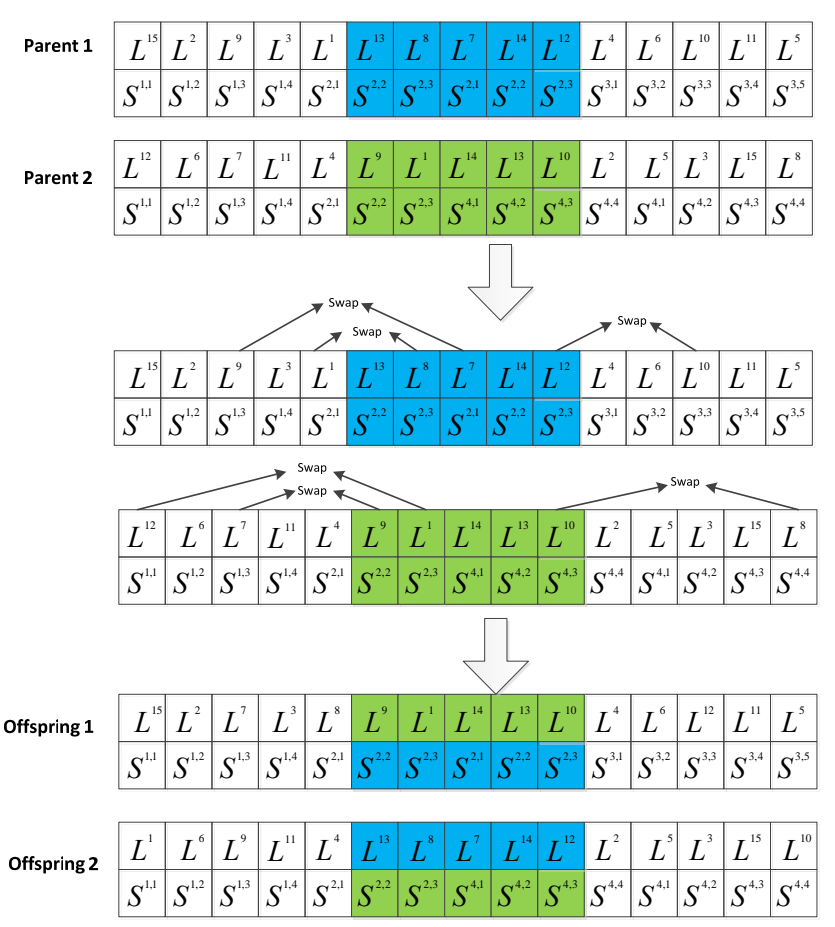

Fig. 4 Work Principle of Partially Matched Crossover

the subtask. There are five preference categories of subtasks: 'very interesting', 'interesting', 'ordinary', 'uninteresting' and 'very uninteresting' corresponding to the preference grades 5,4 , $3,2,1$, respectively.

The number of task schedules that can be published by one learner is not limited, while learners are encouraged to use their imagination to supply further ideas. The authority of accessing the Bulletin Service is differentiated into four levels. Take the example of a published task schedule:

- Its publisher can upload/modify/check the task schedule, accept/reject modifications from other learners, and give expected-achievable values and preference grades.

- $\quad$ The publisher's teammates (from the same original team of the Jigsaw Classroom) can modify/check task schedule, and give expected-achievable values and preference grades.

- Learners from other original teams can check the task schedule and give preference grades.

\subsection{The Inference Service}

The Inference Service is the core of our solution and it is this service which attempts to tackle the problems caused by the specialization of mobile cloud-based learning.

Referring the capabilities and the preferences of learners, and the expected-achievable values of subtasks, the operation principle of this service is trying to match each learner to the most appropriate subtask. On the other hand, in the inference process, learners who are assigned subtasks belonging to the same task will be grouped into the same team, so that the combined strengths of a team are taken into consideration. Let us imagine two team formation scenarios:

- $\quad$ 'Keeping the balance between each team', which means the upcoming teams will have similar comprehensive teamwork skills. In addition, the learners' preferences and capability levels are diverse in confined shapes, meaning that if we regard each team as an independent unit, its integrated preferences and capability values are very close to those of other units. Therefore, we assume that the inter-team competition between the upcoming teams starts from the same point and is inherently fair.

- $\quad$ 'Letting the learners show their capabilities in the best possible way', which means each learner is able to put their strengths to use as much as possible, so that whether the team members are 'good at' and 'happy in' doing their upcoming subtasks will be the main indices that direct the reasoning process of the task allocation.

The detailed inference process based on the GA will be discussed in Section 5.

\subsection{The Monitor Service}

Given that each learner is allocated a subtask and grouped into a team using the Inference Service, the Monitor Service invokes all the team information to coordinate learners into mutual supervision, when team-based learning is in progress.

The Monitor Service takes part in two preparatory steps before learners start their work. First, for each allocated subtask, it checks the period of each stage, and sets a time milestone at the break between two stages as the trigger for message notification. For example, if a subtask has three stages, the periods of each are 3 days, 5 days, and 5 days. Once the team learning starts, the Monitor Service sends a message after 3 days to the performer of the subtask to notify him/her that the first stage is over, and then sends the second message 5 days later and the third message after another five days. Second, in each team, it appoints a leaner as the coordinator for each subtask who is not the performer responsible for accomplishing the subtask.

For each subtask, once the performer responsible gets a message that a stage is over, s/he is asked to submit his/her periodical achievement. A file transmission channel links him/her with the coordinator for each subtask, and s/he can use it to automatically transfer the periodical achievement to his/her coordinator. Downloading and reviewing the file, the coordinator takes responsibility for judging whether the rate of progress is satisfactory and whether the performer would be capable of continuing or not, by grading the progress as 'satisfactory' or 'unsatisfactory'. If an 'unsatisfactory' grade is given, the coordinator is required to decide how much 'extra time' should be given for work revision. A new message is sent to the performer when the 'extra time' ends, at which time the revised work must be resubmitted. Then the coordinator judges it again.

If a performer receives an 'unsatisfactory' multiple times, the Monitor Service holds a vote among his/her team. Each team member is shown his/her latest outcome and, after reviewing it, chooses one of the two options, 'continue' or 'warning'. All vote results are collected to reach a consensus, while the performer is allowed to start the next stage of his/her work. Then the coordinator gives a mark to the performer for this stage. A penalty mechanism is embedded in this service which automatically reduces the performer's marks if s/he gets any 'unsatisfactory' or 'warning' grade on a stage of his in-progress work. All lost marks are accumulated and fed back to teachers at the end of team learning. 


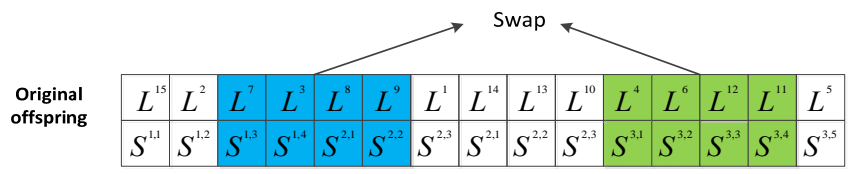

\begin{tabular}{c|c|c|c|c|c|c|c|c|c|c|c|c|c|c|c|}
\multirow{4}{*}{$\begin{array}{c}\text { New } \\
\text { offspring }\end{array}$} & $L^{15}$ & $L^{2}$ & $L^{4}$ & $L^{6}$ & $L^{12}$ & $L^{11}$ & $L^{1}$ & $L^{14}$ & $L^{13}$ & $L^{10}$ & $L^{7}$ & $L^{3}$ & $L^{8}$ & $L^{9}$ & $L^{5}$ \\
\cline { 2 - 11 } & $S^{1,1}$ & $S^{1,2}$ & $S^{1,3}$ & $S^{1,4}$ & $S^{2,1}$ & $S^{2,2}$ & $S^{2,3}$ & $S^{2,1}$ & $S^{2,2}$ & $S^{2,3}$ & $S^{3,1}$ & $S^{3,2}$ & $S^{3,3}$ & $S^{3,4}$ & $S^{3,5}$ \\
\hline
\end{tabular}

Fig.5 Work Principle of Uniform Mutation

\section{GA FOR THE INFERENCE SERVICE}

The solution space of the task allocation problem is very large, being up to $k$ !, where $k$ is the number of learners. Hence, we attempt to use the heuristic algorithm to find feasible solutions without huge time consumption. In this Section, we will introduce the GA-based method, one of the widely adopted heuristic algorithms, which will be executed by the Inference Service.

\subsection{Problem Modeling}

For initialization, the Inference Service checks whether learner $L^{k}$ is appropriate to accomplish an $S^{i, j}$ by specific calculations. We introduce two variables to describe the deviations of social features between the learner and the subtask. The first variable $D e P$ denotes the preference gap between the learner's ideal and reality, where:

$$
D e P_{k}^{i j}=5-P_{k}^{i j}
$$

As the highest grade of preference is 5, the equation (5) is derived from the single-dimensional Euclidean distance, which is the arithmetical difference between the highest grade and the specific chosen grade.

And the second variable $D e K$ denotes the deviation of the learner's KLS capability values versus a subtask's expectedachievable values, where:

$$
D e K_{k}^{i j}=-\left\{\operatorname{sign}\left[\sum\left(K L S^{k}-S T^{i j}\right)\right]\right\} \cdot\left\|K L S^{k}-S T^{i j}\right\|
$$

Subject to:

$$
\begin{aligned}
& K L S^{k}-S T^{i j}=\left\{A C^{k}-A C^{i j}, A S^{k}-A S^{i j}, C^{k}-C^{i j}, D^{k}-D^{i j}\right\} \\
& \left\|K L S^{k}-S T^{i j}\right\|=\sqrt{\begin{array}{l}
\left(A C^{k}-A C^{i j}\right)^{2}+\left(A S^{k}-A S^{i j}\right)^{2} \\
+\left(C^{k}-C^{i j}\right)^{2}+\left(D^{k}-D^{i j}\right)^{2}
\end{array}}
\end{aligned}
$$

In the case of both of these deviations, the lower the better. An ideal $D e K_{k}^{i j}$ is below 0. Equation (7) is a computation to judge whether the value of Equation (6) is positive or negative. Equation (8) is the four-dimensional Euclidean distance between the expected-achievable value of a specific subtask and an individual learner's KLS capability values.

If potential team $x$ is allocated with task $i$, we use ${ }^{x} D e P^{i}$, ${ }^{x} D e K^{i},{ }^{x} C T^{i}$ to represent its sum of $D e P, D e K, C T$, respectively.

\subsection{GA- Based Method}

GA is an optimal self-adaptive heuristic algorithm which simulates the natural biological selection and genetic evolution mechanism. The basic idea of GA is inspired by the evolution process in the natural world, to optimize candidate solutions towards better ones [66] [67]. Traditionally, candidate solutions start randomly and change over generations, by selection, crossover and mutation. Every generation is evaluated by a

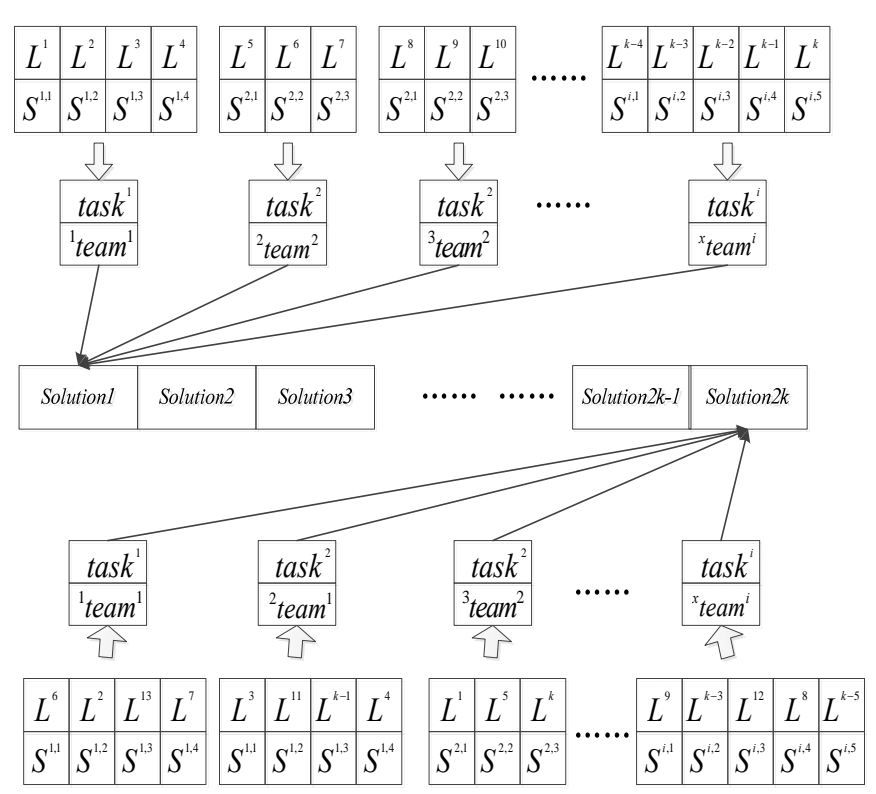

Fig. 3 An Example Process of Genome Encoding

fitness function and the new generation is then used in the next iteration of the algorithm. Once a satisfactory fitness level has been reached, the iterations terminate and the algorithm outputs the final generation as the optimal solution.

To start the GA operation, arrays of $k$ learner/subtask pairs are randomly generated, where $k$ is the number of learners. In each array, the integrities of tasks should be checked. If there is any overflowing subtask within, that array will not be adopted as the initial solution. Taking these initial solutions as individuals (chromosomes), we need to encode them into populations (genomes) for creating the first generation. An example process of genome encoding is shown in Fig. 3.

A fitness function transfers the task allocation from multiobjective optimization to single-objective optimization. For the first scenario mentioned in Section 4.4, to obtain the proximate ${ }^{x} \mathrm{CT},{ }^{x} \mathrm{DeP} \mathrm{P}^{i}$ and ${ }^{x} \mathrm{DeK} \mathrm{K}^{i}$ between teams, total teams' variances of these parameters should be respectively minimized. However, for each attribute, several solutions may have different means but with the similar variances. A special situation is that the original difference of potential teams is little. To avoid the evaluation to blindly terminate in a partial balance, we take minimizing the means of the $D e P$ and the $D e K$ of all teams into consideration. So we use the next equation as the fitness function:

$$
\begin{aligned}
& R_{m}=\alpha \sqrt{\frac{1}{n} \sum_{i=1}^{n}\left(\frac{{ }^{x} C T^{i}}{N^{i}}-\overline{C T}\right)^{2}}+\beta \sqrt{\frac{1}{n} \sum_{i=1}^{n}\left(\frac{{ }^{x} D e P^{i}}{N^{i}}-\overline{D e P}\right)^{2}} \\
&+\gamma \sqrt{\frac{1}{n} \sum_{i=1}^{n}\left(\frac{{ }^{x} D e K^{i}}{N^{i}}-\overline{D e K}\right)^{2}}+\varepsilon \overline{D e P}+\eta \overline{D e K}
\end{aligned}
$$

For the second scenario, in a candidate solution, minimizing the total $\mathrm{DeP}$ and $\mathrm{DeK}$ is more important than minimizing the variance of $C T$, so we take the following fitness function:

$$
R_{m}=\alpha \sqrt{\frac{1}{n} \sum_{i=1}^{n}\left(\frac{{ }^{x} C T^{i}}{N^{i}}-\overline{C T}\right)^{2}}+\sum_{i=1}^{n}\left(\beta^{x} D e P^{i}+\gamma^{x} D e K^{i}\right)
$$

where each Greek letter in (9) and (10) represents the weight for that attribute, hence, the controlling parameter in our algorithms. 
The aim of selection operator is to remove the poor solution with higher fitness. Then the selected individuals evolve to the next generation through the effect of crossover operator and mutation operation. We choose the top percent selection as the selection operator, the partially matched crossover as the crossover operator and the uniform mutation as the mutation operator. In particular, it should be noticed that the partially matched crossover has the function to deal with the appearance of the unfeasible solution that, after crossover, in a genome, a learner is repetitively assigned while another learner is left out. The work principles of the partially matched crossover and uniform mutation are shown in Fig. 4 and Fig. 5, respectively. Let the population size is $2 k$. The pseudo code of GA is shown below:

The pseudo code of GA

Input: $\quad K L S^{k}, C T^{k}, S T^{i j}, P_{k}^{i j}, N^{i}$
Output: Team ${ }^{x} /$ Task $k^{i}$ pairs (sets of $L^{k} / S^{i, j}$ pairs)

begin: Calculate DeP, DeK, CT.

Randomly generate arrays of $k L^{k} / S^{i, j}$ pairs

Check the task integrity in each array, give up unmatched ones.

Take the matched individuals as the initial population. Make the population size as $2 k$.

// genome encoding as shown in Fig.3

for each individual $\in$ population do

Evaluate the fitness of each individual using $R_{m}$.

/lequation (9) or (10)

end for

while iteration times $<$ max iteration time do

Select the individuals with lower fitness.

Use crossover operator to produce offspring.

//partially matched crossover as shown in Fig.4

Operate offspring through mutation operator.

//uniform mutation as shown in Fig.5

Evaluate the fitness of new individuals using $R_{m}$.

/lequation (9) or (10)

Take the lower-fitness individuals to replace the old ones.

end while

Output the task allocation.

end

\section{EXPERIMENTS AND SYSTEM IMPLEMENTATION}

\subsection{Evaluation of Genetic Algorithm}

In order to show the performance of the genetic algorithm method for the task allocation inference, we have coded the algorithm using the MATLAB tool. To simulate the learning scenario we described above, the data of learner information and task/subtask is randomly generated by MATLAB, obeying normal distribution. For the experiment, we set the crossover possibility of the GA at 0.9 , the mutation possibility at 0.2 , and the terminal condition is iteration for 500 times. The population of learners is chosen to be 100 persons and the number of subtasks is 200. In the first scenario, we set the weights $\alpha=0.5$, $\beta=0.15, \gamma=0.25, \varepsilon=0.05, \eta=0.05$. In the second scenario, we set the weights $\alpha=0.2, \beta=0.4, \eta=0.4$.

Having met the terminal condition, the algorithm outputs a solution, including 100 learner/subtask pairs, for allocating learners to their most appropriate subtasks. From Fig. 6 and Fig. 7, in the first scenario, we can find that learners are divided into 20 teams and the values of total $C T, D e P$ and $D e K$ of each team are separately balanced on the nearly same levels. The three attributes between teams are all in close proximities, which mean that the teams have almost equal capabilities and preferences to achieve goals of their responsible tasks. And in the second scenario, as the solution grouped learners into 22 teams, the $D e K$ attributes of each team are below 0, so that each team is competent to their allocated task. The result shows that the $D e P$ level of each team is less than 3 . Because the team size is 3 to 6 persons, this means the allocated tasks are enjoying high preferences as them being deemed better than "interesting".

Consequently, we can claim that the GA method is feasible to achieve the optimal task allocation, for both the first scenario and the second scenario. That is to say, though the attributes of learners and subtasks are complex, our GA method has the ability to seek the proper team formation not only taking the individual learning style of each learner and comprehensive skills of each team into account, but also ensuring each team to have competitiveness and fulfill different learning demands.

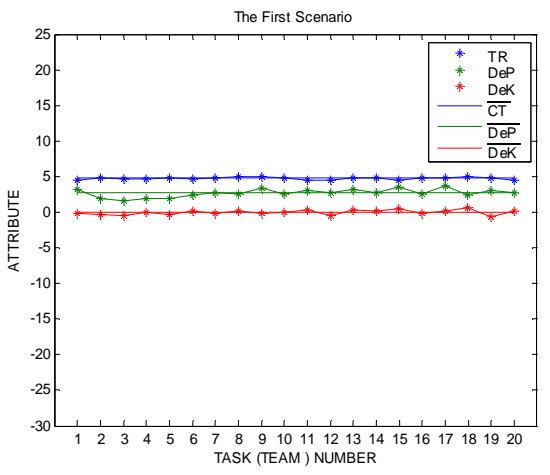

Fig.6 Task Allocation for the 1st Scenarios by GA 


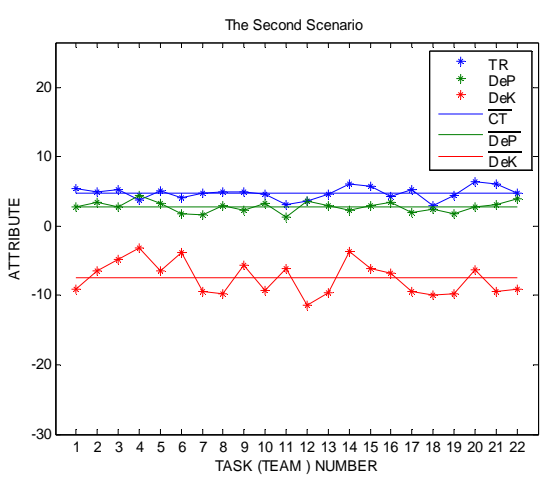

Fig.7 Task Allocation for the $2^{\text {nd }}$ Scenarios by GA

\subsection{System Implementation}

We employ MOODLE, a well-known open source LMS, as our test LMS, by composing the TaaS and MOODLE to execute a teamwork-enhanced learning flow for mobile cloud-based learning. The working principle is that mobile learners access learning resources and perform their conventional learning activities through MOODLE, whereas they utilize functions supported by TaaS to facilitate collaborative learning.

To deploy our TaaS, we have launched a Linux instance, which contains one or a cluster of computers, of the Amazon Elastic Cloud Computing (EC2), running in Virginia, USA. We have configured the server environment as Apache + PHP + Mysql, and hosted our TaaS package on it. We have also uploaded the system package of MOODLE into the Amazon EC2, hosted on the same instance.

As shown in Fig. 8, we have integrated the five services introduced in Section 3 as a system and added a usermanagement module for controlling accounts. Abbreviations in this class diagram can be referred to the Section 4 and Section 5 , and the Web methods provided by each service are also listed. The single-sign-on (SSO) technique is realized to enable users (teachers and learners) to log in to TaaS if they have valid MOODLE accounts. We have created a new database of TaaS for storing teamwork-related data, such as learners' KLS capabilities, preferences, etc, meanwhile basic learning information, such as learner name, course name, etc, are invoked from MOODLE through its Web service APIs, namely, core_user and core_course. TaaS automatically updates any changes of team information to MOODLE by invoking the core_group API.

\subsection{User Interfaces}

The screenshots of UI on the next pages are caught from a Samsung Tablet, running Android 4.0 OS. Users are free to access TaaS and cloud-hosting LMSs by simple operation (e.g. finger actions on the touch screen) through their mobile devices, while the whole computing process is handled over the cloud.

The UI of teachers' main page of TaaS is shown in Fig. 9. Teachers can click buttons to launch several events, such as starting each stage of the Jigsaw Classroom and activating grouping by triggering the Inference Service. They also have authorities to change the structure of surveys, pre-set the penalty mechanisms embedded in the Monitor Service (set the maximum times allowed for a learner to get 'unsatisfactory' grade, the deduction weight for each 'unsatisfactory' and 'warning').

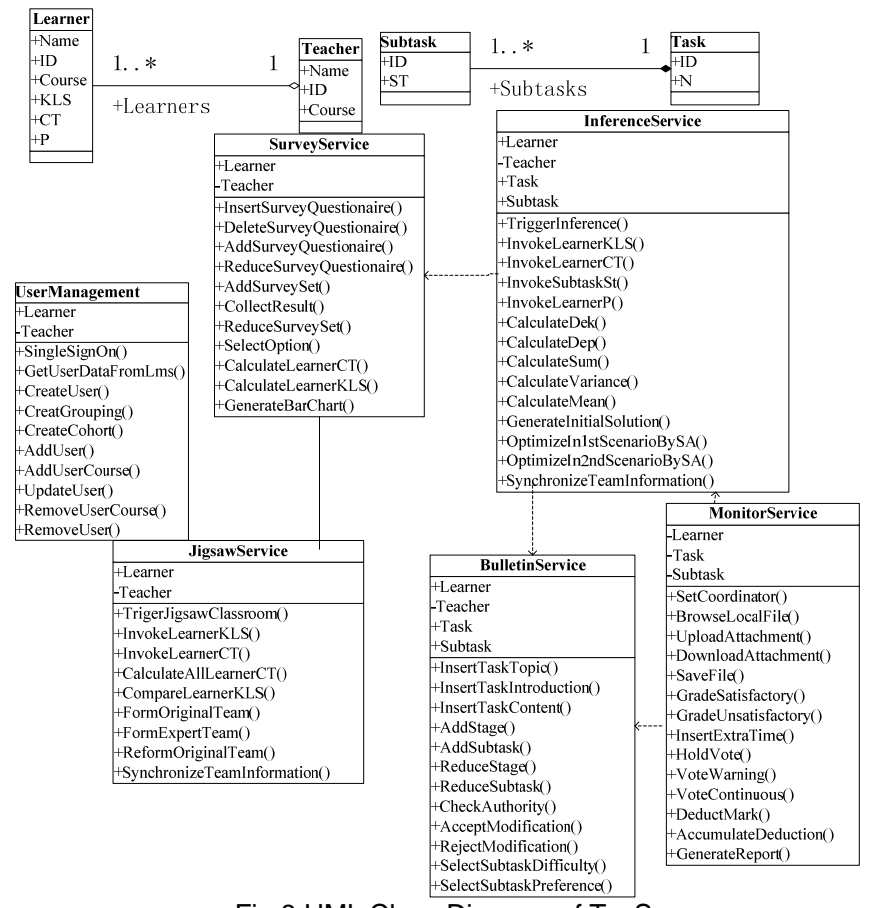

Fig.8 UML Class Diagram of TaaS

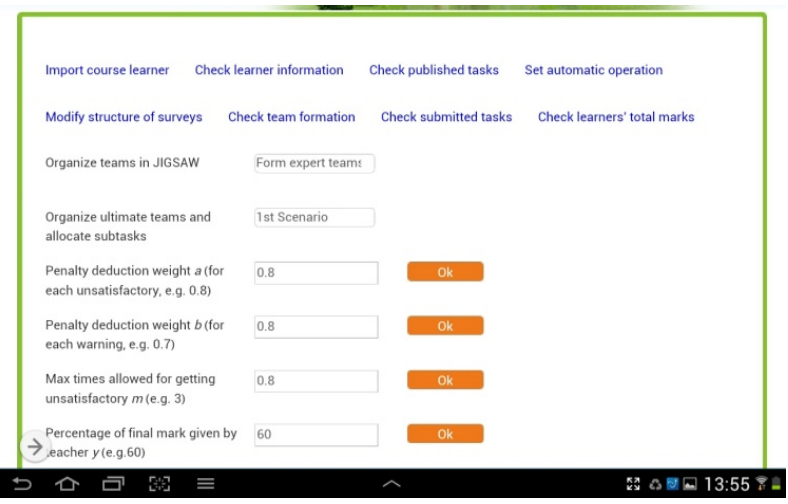

Fig. 9 Main Page of the Teacher User

The teacher user can check the team formation by clicking the corresponding button, an example UI is shown as Fig. 10.

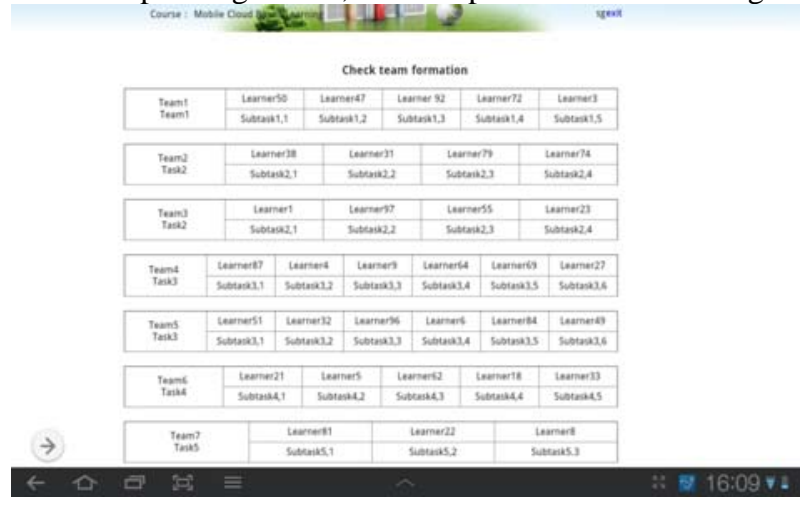

Fig. 10 Example UI of Checking Team Formation (Ultimate Teams Grouped by the Inference Service)

The UI of learners' main page is shown as Fig. 11. Learners' capabilities in five areas are summarized in a bar chart, and can be checked by their teammates. They can click buttons to participate in learning activities by entering new pages. For 
example, the "Participate in survey" button works for showing learners the interface of answering the five sets of questionnaires pre-installed in the Survey Service. The status of the message box changes when the new announcement arrives. Their team information and task information are shown on the bottom of the main page.

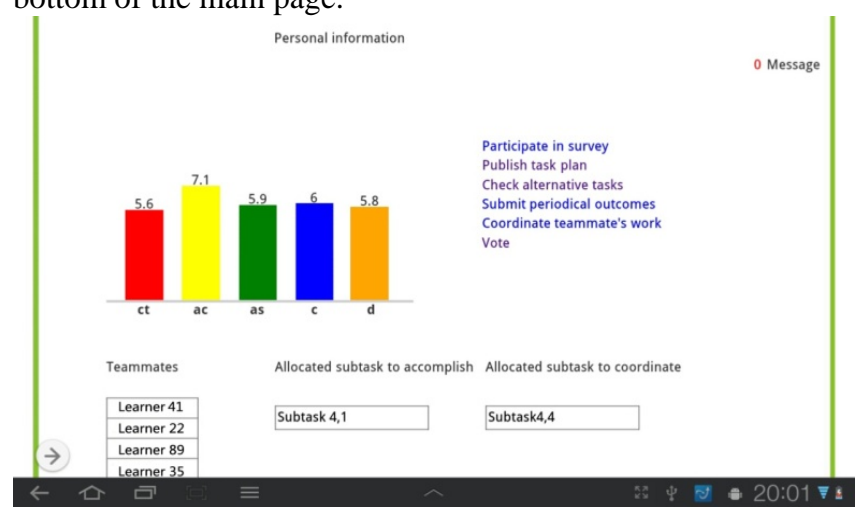

Fig. 11 Main Page of the Learner User

While they are planning schedules using the Bulletin Service, the structure of tasks is scalable, by adding/reducing subtasks and adding/reducing the stages of subtasks. The example UI is shown as Fig. 12.

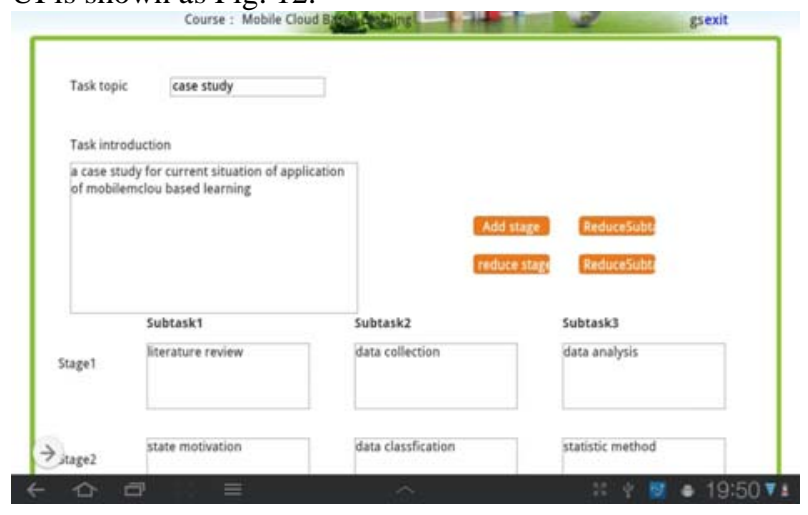

Fig. 12 Example UI of Publishing Tasks in the Bulletin Service

As each learner is potentially a coordinator for one of his/her teammates, s/he can click the "Coordinate teammate's work" button to deal with this job. The example UI for processing mutual supervision is shown as Fig. 13.

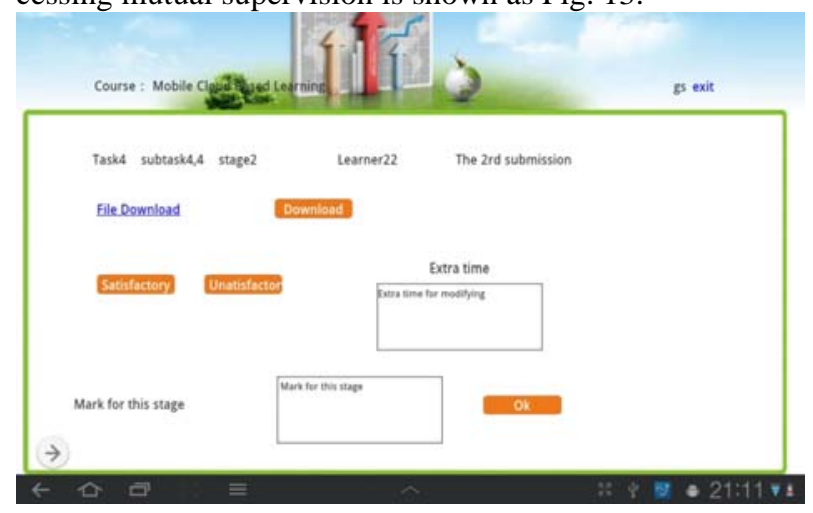

Fig. 13 Example UI of Processing Mutual Supervision

\section{Discussions}

On-demand service is a prominent feature of cloud computing. Owing to the fact that web services in the cloud environment are loosely coupled, the architecture of service-oriented systems is flexible. TaaS is therefore customizable, depending on the teaching plan. Parts of these five web services can be decoupled or re-coupled to work individually to meet special requirements.

In most cases, however, the use of the integrated system is recommended for enhancing teamwork performance. In mobile environments, learners' behaviors and abilities vary greatly, while teamwork is more related to human-to-human interactions rather than human-to-machine interactions. Even though collaborative learning tools are not rare in the current Internet environment and the use of social network is increasing because of the convenience of digital communication, the learning activities of virtual teams are still hard to maintain, due to difficulties such as incompatibilities between different learners' abilities and learning styles. Thus, it is very important for an online system to contribute to the guidance and regulation of what learners do offline, so as to maintain progress towards their common goals. Additionally, as TaaS exposes standardized service-oriented APIs that allow dynamic integration over the Web, they can be easily invoked by external services and work seamlessly in conjunction with LMSs for building a functioncomplete virtual learning environment (VLE).

TaaS is designed with the assistance of social computing. It has the ability to solve problems which could undermine the work of the whole team. We are testing TaaS with MOODLE in real environments at our university on-campus online course delivery system, where a group of courses are being monitored to evaluate how such an add-on system can help teachers and improve learners' learning experiences, particularly in the performance of team work.

\section{CONCLUSION AND FUTURE WORK}

Mobile cloud-based learning promotes the benefits and convenience of distance learning, but current research has not provided ways to facilitate collaborative learning in such a new context. In this paper, we draw on the idea of social computing to fill that gap, helping the virtual team to perform better in online courses. We consider learners' social features: their capabilities, learning styles and preferences, and the objective conditions of the assignments or other assessments they are facing. We develop tools to support them to be more focused on teamwork, and the computationally sound choices would also help them to get into more suited collaborative learning scenarios.

The main contributions of this paper are:

- We have followed the KTLE to orchestrate a mobile cloud-based learning flow, which consists of necessary steps to build a successful team.

- $\quad$ The execution of the new learning flow is realized by running cloud based web services combined with a popular LMS (i.e., MOODLE), where each of the services contribute functions by adding refined learning activities into the original teamwork processes. Using these web services, learners are able to deepen their understanding of team learning purpose, practice their planning capabilities 
and supervise other team members to avoid delays and guarantee efficiency.

- Additionally, considering the limitation of less face-toface communication in the mobile environment, we introduce a new approach for task allocation. This approach focuses on assigning learners highly suited tasks. As the attributes of candidate learners and tasks are complex, a genetic algorithm method is utilized to computationally determine the task allocation. Initial experimental results show that the method functions effectively in real mobile cloud-based learning. The usability and feasibility study is currently ongoing with generally positive feedback gained from learners in different subjects with various class and group sizes.

- We also have implemented these mobile-accessible web services over the Amazon EC2 cloud.

Our future work will focus on offering a client application for easier use through mobile devices, and we will also complete the empirical case studies to analyze learners' teamwork performance after they are assisted by TaaS. Because our mathematical model is extensible, other aspects of social features or social knowledge may also need to be considered in order to provide better prediction for the social context. New exciting opportunities are worth investigating how team members adapt to new pedagogical environments in the social network era.

\section{REFERENCES}

[1] Sharples M, Corlett D, Westmancott O (2002) The Design and Implementation of a Mobile Learning Resource. Personal and Ubiquitous Computing 6 (3):220-234

[2] Wentling TL, Waight C, Gallaher J, Fleur J, Wang C, Kanfer A (2000) e-learning - A Review of Literature, Knowledge and Learning Systems Group. NCSA, University of Illinois at Urbana-Champaign, Illinois, USA

[3] Moodle (2013). https://moodle.org/.

[4] Blackboard (2013). http://www.blackboard.com/International/APAC/ Overview.aspx.

[5] Docebo (2013). http://www.docebo.com.

[6] Mell P, Grance T (2009) Draft NIST Working Definition of Cloud Computing. National Institute of Standards and Technology, USA.

[7] Vouk MA (2008) Cloud Computing-Issues, Research and Implementations. Journal of Computing and Information Technology 16 (4):235-246.

[8] Kim SH, Mims C, Holmes KP (2006) An Introduction to Current Trends and Benefits of Mobile Wireless Technology Use in Higher Education. Association for the Advancement of Computing in Education Journal 14 (1):77-100.

[9] Bermejo S (2005) Cooperative Electronic Learning in Virtual Laboratories through Forums. IEEE Transactions on Education 48 (1) : 140-149.

[10] Baskerville R, Nandhakumar J (2007) Activating and Perpetuating Virtual Teams: Now That We Are Mobile, Where Do We Go? IEEE Transactions on Professional Communication 50 (1) : 17-34.

[11] Kayes AB, Kayes DC, Kolb DA (2005) Developing teams using the Kolb team learning experience. Simulation \& Gaming 36 (3):355-363.

[12] Wang FY, Carley KM, Zeng D, Mao W (2007) Social Computing: From Social Informatics to Social Intelligence. IEEE Transactions on Intelligent Systems 22 (2):79-83.

[13] Dron J, Anderson T (October 2007) Collectives, Networks and Groups in Social Software for E-learning. Paper presented at the
World Conference on E-Learning in Corporate, Government, Healthcare, and Higher Education (ELEARN), Quebec City, Canada.

[14] Law N, Miyake N, Looi CK, Vuorikari R, Punie Y, Linn M (June 2013) Are CSCL and Learning Sciences research relevant to large-scale educational reform? Paper presented at the 10th International Conference on Computer Supported Collaborative Learning (CSCL), Madison, USA.

[15] Kirschner PA, Erkens G (2013) Toward a Framework for CSCL Research. Educational Psychologist 48 (1): 1-8.

[16] Liao J, Wang M (October 2011) A collaborative learning system based on cloud and e-commerce. Paper presented at the 8th IEEE International Conference on e-Business Engineering, Beijing, China.

[17] Downes S (2006) Learning Network and Connective Knowledge. IT Forum in Miscellaneous Publications, University of Geogia.

[18] Popov V, Noroozi O, Barrett JB, Bieman HJA, Teasley SD, Slof B, Mulder M (2014) Perceptions and Experiences of, and Outcomes for, University Students in Culturally Diversified Dyads in a Computer-Supported Collaborative Learning Environment. Computers in Human Behavior 32: (186-200).

[19] Wellman B, Salaff J, Dimitrova D, Garton L, Gulia M, Haythornthwaite C (2001) Computer Networks as Social Networks: Collaborative Work, Telework, and Virtual Community. Science 293 (14):2031-2034.

[20] Sobrero PM (2008) Social learning through virtual teams and communities. Journal of Extension 46 (3).

[21] Saunders CS, Ahuja MK (2006) Are All Distributed Teams the Same? Differentiating Between Temporary and On-going Distributed Teams. Small Group Research 37 (6):662-700.

[22] Ebrahim NA, Ahmed S, Taha Z (2009) Virtual Teams: a Literature Review. Australian Journal of Basic and Applied Sciences 3 (3):26532669.

[23] Schwabe G, Goth C, Frohberg D (July 2005) Does Team Size Matter in Mobile Learning. Paper presented at the International Conference on Mobile Business (ICMB), Sydney, Australia.

[24] Wu T, Liu D, Bi X (2006) Team Learning Orientation and Conflicts Influence Team Performance in Differ-ent task Difficulties. Paper presented at the IEEE International Conference on Advanced Management Science, Chengdu, China.

[25] Franzoni AL, Assar S (2009) Student Learning Styles Adaptation Method Based on Teaching Strategies and Electronic Media. Educational Technology \& Society 12 (4):15-29.

[26] Koh E, Lim J (2012) Too Early, Too Bad: Uncovering and Understanding the Initial Participation Para-dox in Technology-Mediated Learning Teams. IEEE Transactions on Professional Communication 55 (1):55-84.

[27] Feldmann B (July 2006) Group Types in E-Learning EnvironmentsStudy Team, Working Team and Learning Team. Paper presented at the 7th International Conference on Information Technology Based Higher Educa-tion and Training (ITHET), Ultimo, Australia.

[28] Pinola M (2011) Mobile collaboration and community tools for virtual teams. In: Woodill G (ed) The Mobile Learning Edge. McGraw-Hill Companies.

[29] Cramton CD (2001) The Mutual Knowledge Problem and Its Consquences for Dispeared Collabora-tion. Organization Science 12 (3):346-372.

[30] Sharples M, Arnedillo-Sanchez I, Milrad M, Vavoula G (2009) Mobile Learning. Technology-Enhanced Learning Springer:233-249.

[31] RW3 Culture Wizard (2010) The challenges of working in virtual teams. Virtual Team Survey Report. New York, USA.

[32] Kukulska-Hulme A, Sharples M, Milrad M, Arnedilo-Sanchez I, G. Vavou-la (2013) Innovation in Mobile Learning: A European Perspective. International Jounal of Mobile and Blended Learning (IJMBL) 1 
(1):13-35.

[33] Raschick M, Maypole DE, Day PA (1998) Improving field education through Kolb's learning theory. Journal of Social Work Education 34 (1):34-42.

[34] Jones C, Reichard C, Mokhtar K (2003) Are students' learning styles discipline specific? Community College Journal of Research and Practice 27 (5):363-375.

[35] Terrell SR, Dringus L (2000) An investigation of the effecti of learning style on student success in an online learn-ing environment. Journal of Educational Technology Systems 28 (3):231-238.

[36] Richmond AS, Cummings R (2005) Implementing Kolb's learning styles into online distance education. International Journal of Technology in Teaching and Learning 1 (1):45-54.

[37] Anagnostopoulos A, Becchetti L, Castillo C, Gionis A, Leonardi S (2012) Online team formation in social networks. World Wide Web, Lyon, France.

[38] Vidyarthi DP, Tripathi AK, Sarker B, Yang LT (2009) GA based Task Allocation Models. In: Scheduling in Distributed Computing Systems-analysis, design and models. Springer.

[39] Page AJ, Keane TM, Naughton TJ (2010) Multi-heuristic dynamic task allocation using genetic algorithms in a heterogene-ous distributed system. Journal of Parallel Distributed Computing 70 (7):758-766.

[40] Wi H, Oh S, Mun J, Jung M (2009) A Team Formation Model Based on Knowledge and Collaboration. Expert Systems with Applications: An International Journal 36 (5):9121-9134.

[41] Tam V, Lam EY, Fung ST (July, 2012) Toward a Complete e-learning System Framework for Semantic Analysis, Con-cept Clustering and Learning Path Optimization. Paper presented at the 12th IEEE International Conference on Advanced Learning Technologies, Roma, Italy.

[42] Fransen J, Weinberger A, Paul A (2013) Team Effectiveness and Team Development in CSCL. Educational Psychologist 48 (1): 9-24.

[43] Liao J, Wang M (October 2011) A collaborative learning system based on cloud and e-commerce. Paper presented at the 8th IEEE International Conference on e-Business Engineering, Beijing, China.

[44] Lee KB, Salman R (2012) The Design and Development of Mobile Collaborative Learning Application Using Android. Journal of Information Technology and Application in Education 1 (1):1-8.

[45] Bochicchio MA, Longo A (October 2011) Collaborative Web Labs as a Service: Challenges and Opportunities. Paper presented at the 41st ASEE/IEEE Frontiers in Education Conference, Rapid City, USA.

[46] Chatti MA (2012) Collaboration in mobile learning. Report of Computer-supported Learning Research Group. RWTH Aachen University, Germany.

[47] Gao H, Baylor A, Shen E (2005) Designer support for online collaboration and knowledge construction. Educational Technology and Society 8 (1):69-79.

[48] Singh S, Rylander DH, Mims TC (2012) Efficiency of Online vs. Offline Learning: A comparison of Inouts and Outcomes. International Journal of Business, Humanities and Technology 2 (1):93-98.

[49] Trifonova A, Ronchetti M (July 2006) Mobile Learning: Is Anytime + Anywhere $=$ Always Online ? Paper presented at the 6th IEEE International Conference on Advanced Learning Technologies, Kerkrade, Netherlands.

[50] Attewell J (2005) A Technology Update and m-Learning Project Summary. Mobile Technology and Learning. Learning and Skills Development Agency, UK.

[51] Wu H, Hamdi L, Mahe N (May 2010) Tango: A Flexible Mobilityenabled Architecture for Online and Offline Mobile Enterprise Applications. Paper presented at the 11th International Conference on Mo- bile Data Management, Kansas City, MO, USA.

[52] Chua FF, Tay ES (July 2012) Developing Virtual Learning Environment 2.0 Using Web Services Apporach. Paper presented at the 12th IEEE International Conference on Advanced Learning Technologies (ICALT), Rome, Italy.

[53] Cao XM, Zhao P, Wang X (May 2009) Study on Design and Development e-Learning System Based on Learning Flow. Paper presented at the World Congress on Software Engineering (WCSE), China.

[54] Aronson E, Blaney N, Steophan C, Sikes J, Snapp M (1978) The Jigsaw Classroom. Beverly Hills, CA, USA.

[55] Millis BJ, Cottell PG (1998) Cooperative Learning for Higher Education Faculty. Phoenix, AZ, USA.

[56] Wang C (2009) The Development of Collaborative Learning Environment with Learning Blogs. Journal of Software 4 (2).

[57] Thiele JE (2003) Learning patterns of online students. Journal of Nursing Education 42 (8):364-367.

[58] Kolb D (1984) Experiential learning: Experience as a source of learning and development. NJ: Prentice Hall, Upper Saddle River, USA.

[59] Kolb AD (2005) Learning styles and learning spaces: Enhancing experiential learning in higher education. Academy of Management Learning and Education 4 (2):193-212.

[60] Belbin R (1993) Team Roles at Work. Butterworth Heinemann.

[61] Loo R (2004) Kolb's learning styles and learning preferences: is there a linkage. Educational Psychology 24 (1):99-108.

[62] Lingard R, Barkataki S (October 2011) Teaching Teamwork in Engineering and Computer Science, Paper presented at the 41st ASEE/IEEE Frontiers in Education Conference, Rapid City, USA.

[63] Lingard R (July 2009) Teaching and Assessing Teamwork in Engineering and Computer Science. Paper presented at the International Symposium on Engineering Education and Educational Technologies (EEET), Orlando, USA.

[64] Richmond AS, Cummings R (2005) Implementing Kolb’s learning styles into online distance education. International Journal of Technology in Teaching and Learning 1 (1):45-54.

[65] Anagnostopoulos A, Becchetti L, Castillo C, Gionis A, Leonardi S (2012) Online team formation in social networks. World Wide Web, Lyon, France.

[66] Andrew JP, Thomas MK, Thomas JN (2010) Multi-heuristic Dynamic Task Allocation Using Genetic Algorithms in a Heteroge-neous Distributed System. Journal of Parallel Distributed Computing 70:758766.

[67] Holland JH (1992) Adaptation in Natural and Artificial Systems. MIT Press, Cambridge, MA, USA. 